\title{
Descentralización y participación en la Barcelona post-olímpica
}

\section{Andrés Walliser Martínez*}

\section{Introducción}

El concepto de participación ciudadana estuvo muy de mocla en los primeros años de la transición. Uno de los grandes desafíos del nuevo sistema que surgió de aquel proceso era la reforma en profundidad del gobierno local tanto desde un punto de vista político como administrativo. Las primeras elecciones locales democráticas en 1979 supusieron el triunfo de partidos de izquierda en las principales alcaldías españolas, todo ello en un contexto de auge de los movimientos sociales, especialmente aquellos cuyas demandas giraban en torno al derecho a la ciudad '. Esta situación fue en parte la que impulsó a los nuevos ayuntamientos democráticos a cobrar consciencia sobre las nuevas formas en que los ciudadanos se relacionaban con el espacio urbano y con las administraciones locales. La gobernabilidad de la ciudad en el proceso de producción del espacio urbano se convirtió en uno de los principales retos para la recién estrenada democracia y la participación ciudadana parecía la fórmula mágica para conseguirlo ${ }^{2}$. El marco imprescindible era una ciudad descentralizada desde el punto de vista político y administrativo.

Desde entonces, el municipio de Barcelona ha sido uno de los pioneros en lo que a la democratización de la vida local y la descentralización se refiere. Se ha tomado como caso a la ciudad de Barcelona por tres razones: la densidad de su tejido asociativo y su tradición asociativa, por la permanencia de una misma opción política en el gobierno municipal a lo largo de todo el período democrático, y finalmente una consecuencia de esto último, el desarrollo de un proceso de descentralización política y administrativa en el ámbito de los distritos que ha dotado de un marco normativo y relacional a la participación ciudadana en los distritos.

El propósito de este artículo es doble, por un lado, analizar el capital social y la cultura asociativa de los habitantes de esta ciudad, y relacionarlos con el desarrollo de la participación en el seno del proceso de descentralización territorial en el marco de la siguiente pregunta: chasta qué punto es la descentralización suficiente para promover la participación ciudadana en Barcelona?

Las hipótesis de partida son las siguientes. En primer lugar, el efecto de las reglas del juego definidas en la descentralización no tienen el mismo impacto en términos de participación en todos los distritos. El capital social va a adoptar diferentes formas según sea la tradición asociativa de sus habitantes.

Por otro lado, tanto la forma que adopte el capital social como las condiciones estructurales del territorio van a influir en las relaciones entre actores y en las formas de resolución de conflictos empleadas.

El proceso de descentralización se inició en Barcelona con la reforma democrática de la administración local e implicó no sólo una mejora en la gestión y administración, sino también una redefinición del concepto de ciudadano y su papel en la ciudad democrática. El análisis de este proceso se ubica en es- 
tas páginas en el debate teórico sobre el gobierno local y el papel del ciudadano en el proceso de producción del espacio urbano.

Por participación ciudadana se entiende la capacidad de influir en el proceso de toma de decisiones en el ámbito institucional local. La participación puede ser formal o informal. Hay dos formas en las que los ciudadanos pueden participar formalmente en el proceso de producción del espacio urbano: vía representación, votando en elecciones; y tomando parte con voz y voto, o sólo con voz en los ámbitos o instituciones locales que ofrecen mecanismos para hacerlo. La participación informal tiene lugar a través de mecanismos extra-institucionales que son empleados para influir en el proceso de toma de decisiones local. La participación informal se articula tanto a través de los movimientos sociales, como de individuos o grupos no organizados.

En el contexto de este artículo, el gobierno local es uno de los principales canales para la participación ciudadana en el proceso de producción del espacio urbano, tanto a través de mecanismos formales como informales de participación. A través del análisis de la estructura del gobierno local es posible explicar parte de la relación entre los ciudadanos y el proceso de producción del espacio urbano.

\section{De habitante a ciudadano}

El concepto de babitante de la ciudad ha evolucionado notablemente en las últimas décadas en relación a las instituciones, especialmente las locales. Desde el concepto de habitante, la persona que simplemente habita el espacio urbano, al de ciudadano hay una gama de categorías que definen un distinto grado de relación con las instituciones locales. En la literatura inglesa sobre la cuestión se desarrolla una interesante categorización, que va desde el habitante entendido como cliente, como usuario, como consumidor y finalmente como ciudadano ${ }^{3}$. Según BuRNs et al., en la relación entre un burócrata y sus clientes, éstos ceden parte de sus derechos de decisión y aceptan las decisiones que se toma por ellos. El usuario, en cambio, tiene la opción de elegir entre diferentes opciones, opinar sobre ellas y rechazarlas si no le satisfacen. Del concepto de cliente a usuario se pasa del paternalismo burocrático al paternalismo gerencial. Por otro lado, los conceptos de consumidor y ciudadano ponen el énfasis en la idea de capacidad de decisión. En cualquier caso, la relación entre demandantes y proveedores de bienes y servicios se inclina hacia los últimos. El concepto "consumidor" describe la relación de una persona hacia un bien o servicio. En términos de HIRSCHMAN, el consumidor podría optar por la salida, es decir, si no le satisface una oferta concreta, puede elegir otra opción. En este contexto, considerar al consumidor de bienes y servicios públicos desde una perspectiva de actor racional puede plantear tres problemas. En primer lugar, la escasez o inexistencia de opciones alternativas, es decir, que no hay opciones de salida viables. En segundo lugar, la relación entre el bien o servicio y el consumidor es distinta en contextos públicos y privados. Finalmente, la capacidad de opción del consumidor se anula en relación a la elección de determinados servicios colectivos ${ }^{4}$.

El concepto de ciudadano traza una línea de separación con respecto al principio de mercado, que no debe ser considerada como necesariamente "agresiva" ${ }^{5}$. La variable que incorpora la ciudadanía va mas allá de la mera opción. El ciudadano tiene capacidad para influir en el proceso de toma de decisiones en sus aspectos más cotidianos, aparte de su derecho a elegir representantes políticos. La existencia de mecanismos de participación en los ámbitos más próximos al ciudadano hace de la descentralización un elemento imprescindible en la democratización de la vida local, por cuanto son las unidades territoriales y administrativas sublocales como los distritos donde las instituciones locales están más al alcance del ciudadano de a pie.

Ciudadanos y consumidores son criaturas económicas y políticas perfectamente compatibles entre sí. Algunos comportamientos corresponden a decisiones individuales, pero otras echan raíces en el contexto social, en identidades y valores, o en nociones como comunidad o confianza. Las relaciones de los ciudadanos con el gobierno local se pueden entender desde los dos conceptos de ciudadano y consumidor. Incrementar la capacidad de influir de los ciudadanos en relación a las instituciones públicas sólo se puede hacer de dos maneras: dando la posibilidad de salida y dotando mecanismos de voz.

El gobierno local puede entenderse como algo más que una institución proveedora de bienes y servicios. La relación entre administradores y administrados no se limita a la gestión y a la administración, sino que guarda relación con la promoción de la cultura cívica y la mejora de la calidad de vida en sentido amplio. En otras palabras, el gobierno local se puede entender como una potencial escuela de democracia. Es la esfera institucional más próxima al ciudadano y, por lo tanto, en la que resulta más fácil la interacción entre ambos actores y la adquisición de una cultura política participativa basada en la experiencia política cotidiana ${ }^{6}$.

El debate sobre la forma que toma la relación entre los habitantes de la ciudad y la administración local se traslada a la forma en la que se define el modelo de gestión. A grandes rasgos, hay dos grandes modelos de referencia en la gestión de lo local. Ambas formas se pueden encontrar en estado puro en ocasiones pero también coexisten con mayor o menor peso en 
el complejo entramado de las políticas públicas locales. Por un lado, está la influencia de las teorías de elección pública (public choice theories) sobre las formas de gestión de lo local y, por otro, los modelos basados en la cooperación de los distintos actores e intereses.

La principal función de los modelos basados en el mercado es administrar servicios en un marco de libre competencia con la empresa privada. Esta tendencia, muy extendida en Estados Unidos, tuvo en Europa su máxima expresión en los postulados de la nueva derecha que surge tras la crisis de los setenta. Desde este enfoque, las instituciones locales deben estar insertas en un mecanismo de mercado a la hora de ofertar sus bienes y servicios, permitiendo a los individuos elegir entre servicios y bienes de consumo colectivo en competencia con la oferta privada. De otra manera, la burocracia institucional y las instituciones de la democracia representativa producen un exceso de oferta que es capitalizado por los políticos para obtener dividendos electorales. En este contexto la descentralización sirve para descargar a la Administración de compromisos y reducirla al máximo, siguiendo criterios de eficiencia basados estrictamente en el costo ${ }^{7}$.

Como se ha sugerido antes, el gobierno local puede ser más que un proveedor de servicios. La organización de la gestión, especialmente en lo que a diseño y ejecución de políticas públicas se refiere, se puede basar en la cooperación entre actores, enfocando estas relaciones desde unil perspectiva no formalista y flexible ${ }^{8}$. Antes que basar la gestión y la provisión de servicios a estrictos mecanismos de mercado fundados en una relación de coste-beneficio, se opta por apoyar y fomentar mecanismos, alternativos a nivel local y sublocal que provean o cooperen en la provisión de servicios a través de las redes sociales que sustentan a la sociedad civil.

La configuración de los actores ciudadanos como proveedores o co-productores de servicios públicos propicia la democratización de la vida local. En este contexto la descentralización es un instrumento de acercamiento a la ciudaclanía y de su participación en el proceso de toma de decisiones. Los principales atributos para que se desarrolle este modelo en condiciones óptimas no es sólo la existencia de un conjunto de mecanismos eficaces de participación que faciliten el acceso al proceso de toma de decisiones y la capacidad de influir, sino también de la existencia de valores como la lealtad, la confianza y la reciprocidad, lo que se ha venido denominando capital social ${ }^{9}$.

El capital social descansa sobre las identidades colectivas que, a su vez, descansan sobre tres pilares básicos. En primer lugar, las creencias, esto es, la construcción de marcos cognitivos relacionados con los fines, el objeto y el lugar donde el proceso se desarrolle. En segundo lugar, las relàciones sociales en las que, a través de la interacción mutua, los individuos ela- boran y negocian identidades comunes, y finalmente, el factor que desafía a los patrones individualistas, la inversión emocional, a través de la que la gente se vincula a una comunidad ${ }^{10}$.

Robert PutNam establece una interesante relación entre capital social y los resultados obtenidos por las instituciones públicas. Él define capital social como las redes sociales y los vínculos de reciprocidad y confianza que se generan entre los miembros de una comunidad a través de la experiencia que genera la interacción social y la cooperación. El principal argumento de Making Democracy Work gira en torno a la siguiente cuestión: ¿cómo la tradición asociativa y el compromiso cívico pueden afectar al comportamiento político? Su principal conclusión se puede resumir en que amplias diferencias en los resultados de las instituciones están directamente relacionadas con la intensidad de la vida asociativa, es decir del capital social. Putnam toma como caso el impacto de la reforma de la política regional que tuvo lugar en Italia en los años setenta. Para ello explica el desarrollo de las reformas con el capital social en el sur y en el norte del país a través de un concepto que él denomina comunidad cívica, que estaría compuesta por cuatro indicadores fundamentales: (1) el compromiso cívico, (2) la igualdad política, (3) solidaridad, confianza y tolerancia y (4) las estructuras sociales de la cooperación (tejido asociativo).

El trabajo de PUTNam, convertido en un clásico, ha generado a su vez una amplia literatura, en muchos casos crítica que ha contribuido a perfilar y perfeccionar el argumento inicial ${ }^{\text {lf }}$.

Entre otros, BOIX y POSNER critican a PuTnam por no desarrollar en profundidad è análisis cualitativo sobre las redes sociales que describe en Italia. Desde el punto de vista de los autores, es imprescindible tener en cuenta que no todo tipo de redes sociales promueven la participación política desde el aspecto de la cooperación y de los otros valores que dan forma a las comunidades cívicas. BoIX y POSNER matizan esta aproximación al concepto de capital social mediante tres cuestiones que hacen referencia a la calidad del capital social, centrándose en aspectos concretos del funcionamiento del tejido asociativo. En primer lugar, el tipo de interacción que tiene lugar en la asociación: es decir, interacción vertical o interacción borizontal, o lo que es lo mismo que ésta está basada en la igualdad o en una relación jerárquica. En segundo lugar, el propósito de la asociación, en otras palabras cuáles son los resultados (outcomes) de la acción social y cómo se emplea el capital social. Las entidades asociativas pueden producir bienes privados y bienes públicos. En la primera de las categorías el principal objeto es el disfrute de los propios participantes, y la coordinación es la pauta que define el funcionamiento de las entidades. Los bienes públicos se basan en la cooperación de los miembros y su principal objeto es el obtener un beneficio para la comunidad en general, es decir, tanto para los participantes como para los no 
participantes. Finalmente, el grado de segregación de las redes sociales puede variar. La segregación puede ser étnica, o religiosa o ideológica.

El papel de la descentralización es fundamental a la hora de explicar la gobernabilidad urbana y el papel de los ciudadanos. El desarrollo de las redes sociales locales y la comunicación fluida con la administración local sólo se puede conseguir mediante una administración local descentralizada. No obstante, ésta no es suficiente, es también necesaria una profunda democratización de la vida política local, no sólo a través de la capacidad de elegir representantes a nivel de las nuevas unidades descentralizadas, que llamaremos sublocales, sino también de la existencia de mecanismos de voz que faciliten la participación, es decir, la capacidad de influir en el proceso de toma de decisiones. Cuanto mayor sea la descentralización, mayores serán las posibilidades de participar por parte de los ciudadanos.

La descentralización tiene dos aspectos: administrativo y político. La descentralización administrativa consiste en la capacidad de las unidades sublocales de ejercer con cierto grado de autonomía ciertas funciones de la administración local, como la distribución funcional de recursos, o la información transparente acerca de la gestión y gobierno. La descentralización política consiste en el grado variable de autonomía política que reciben las unidades sublocales respecto de la administración local central. La descentralización política puede ir desde la posibilidad de elegir concejales de distrito mediante una lista abierta, hasta el diseño e implementación de las políticas públicas en el distrito. Precisamente, un elemento decisivo de la descentralización política es la existencia de mecanismos de participación que permitan influir a los ciudadanos en ese proceso.

Hasta aquí hemos discutido los distintas relaciones que se establecen entre los habitantes de la ciudad y la administración local y hemos visto los dos grandes modelos que definen la manera en que esas relaciones conforman la gestión y las políticas públicas locales. Son dos opciones que en la práctica conviven, de forma necesaria, en las administraciones locales si bien con distinto grado de proporción.

El capital social juega asimismo un papel importante a la hora de entender el desarrollo de procesos institucionales como la descentralización y su impacto sobre la democratización de la vida local.

La experiencia barcelonesa de gobierno urbano se situaría más próxima al segundo modelo que al primero, si bien hay una clara coexistencia de ambos absolutamente imprescindible. A continuación vamos a ver hasta qué punto un proceso de reforma administrativa y política como es la descentralización municipal de Barcelona puede influir sobre las distintas expresiones del capital social que se dan en la ciudad y en las relaciones entre actores, y, en definitiva, sobre la participación de los ciudadanos en el ámbito territorial.

\section{Barcelona: participación en una ciudad descentralizada}

\section{Asociacionismo y capital social en Barcelona}

En la presente sección se va a dar cuenta de los orígenes del tejido asociativo barcelonés y el capital social sobre el que se sostiene, haciendo hincapié en sus primeras manifestaciones, en la importancia del movimiento vecinal en el ocaso de la dictadura y primeros años de la democracia para las relaciones entre actores urbanos, y finalmente los desarrollos posteriores.

La noción de asociación proviene de la agrupación de un conjunto de personas que se juntan para conseguir una serie de objetivos que están más allá de sus posibilidades como individuos. Los medios empleados para conseguir esos objetivos pueden cambiar con el tiempo. El hecho asociativo y su desarrollo guarda una importante relación con el contexto histórico y social del momento. En el caso de Cataluña, el asociacionismo está determinado por su historia y por el carácter de sus instituciones. El hecho de que en el pasado ha habido instituciones políticas y legales específicas ha influido la aparición de nuevas formas asociativas ${ }^{10}$.

Desde mediados del siglo diecinueve, los movimientos sociales tradicionales se desarrollaron en Cataluña con la industrialización y el crecimiento de los núcleos urbanos. Los movimientos sindicales cobraron en seguida enorme importancia pero también fueron objeto de fuerte represión lo que les convertía en vulnerables y frágiles ". La represión atacaba las bases organizativas de los sindicatos que quedaban desmantelados cada vez que la tensión social subía demasiado. A la luz de esta situación nuevas formas organizativas surgen en el seno del movimiento obrero. Estas entidades no estaban relacionadas directamente con la lucha política, como escuelas laicas, clubes (ateneos y casinos) o centros cívicos. Las federaciones y asociaciones de gremios conformaron también en este período un tejido asociativo basado en cooperativas de producción y consumo. La importancia del asociacionismo y del capital social que se generaba en su seno era de tal importancia en aquellos años que el lema del movimiento obrero en Cataluña era "Asociarse o morir. 
Más adelante, los ateneos fueron ganando importancia como medios de mejorar el nivel cultural de sus miembros, mediante conferencias, cursos, seminarios y bibliotecas. El desarrollo de estas instituciones hizo que se convirtieran, sobre todo las de las clases medias, en importantes focos de debate científico-cultural. Para muchos trabajadores y sus familias eran el único acceso a recursos culturales como la enseñanza para adultos o material impreso. Otro importante pilar del asociacionismo en Cataluña eran las Mutualidades, que cubrían a los trabajadores con una protección mínima contra la inestabilidad en el trabajo, enfermedades y los accidentes laborales. Todas estas entidades daban forma a densas redes sociales con fuertes componentes de identidad colectiva y cooperación, y muy vinculadas al ámbito territorial.

El asociacionismo cultural también se desarrolló en los distintos estratos sociales durante este período. Socialistas, católicos y la alta burguesía tenían cada uno su propio contexto asociativo. En las clases medias y trabajadoras se desarrollaron infinidad de entidades vinculadas a la danza y el canto (esbarts, corales, coros de Clavé, etc.). La alta burguesía industrial y comercial también generó sus propias redes asociativas en torno a símbolos socio-culturales como el Liceu o él Palau de la Música.

Con la Segunda República, el ámbito asociativo creció enormemente, mientras que a partir de 1939 cualquier iniciativa asociativa relacionada con la reivindicación política y social o la cultura catalana fue proscrita. Dos cuestiones van a condicionar la vida asociativa catalana y del Estado desde los años cincuenta en adelante. Un fuerte proceso de transformación del entorno urbano y social tuvo lugar a raíz de la industrialización del país, lo que significó la llegada masiva de inmigrantes empobrecidos del medio rural. Por otro lado, la falta de control sobre la especulación y una negligente planificación urbana que incidirá profundamente sobre el problema de la vivienda.

En este contexto se produce la paulatina reaparición de una cultura catalanista democrática a través de los restos de las redes asociativas: parroquias, grupos excursionistas, asociaciones de estudiantes y, algo después, las primeras asociaciones de vecinos en los barrios de inmigrantes. Ambas tendencias se desarrollaban en los escasos intersticios legales que la legislación franquista permitía. La conciencia anti-franquista creció bajo expresiones culturales y políticas catalanistas y de cultura obrera, que conformaron un importante capital social en términos de asociaciones y entidades de todo tipo ${ }^{14}$.

Durante lós últimos años de la dictadura, el conflicto obrero y urbano se materializó en las fábricas y los barrios. Las asociaciones de vecinos canalizaron las reivindicaciones políticas y estrictamente urbanas. Las principales características de los movimientos sociales urbanos se pueden resumir en los siguientes puntos: a) se autovinculan a la ciudad o a lo urbano, b) están basados en la localidad y se definen territorialmente y c) se movilizan en torno a tres objetivos: consumo colectivo, identidad cultural y autogestión política ${ }^{15}$. La definición del espacio urbano y la autopercepción como ciudadanos con derecho a participar en el proceso de producción del espacio urbano, fueron el principal motor para que surgieran las primeras federaciones de asociaciones de vecinos en Barcelona, que hicieron causa común a partir de 1972 y a lo largo de la transición a la democracia. En todos los barrios se elaboraron planes urbanísticos populares cuestionando el modelo urbano oficial, como respuesta a los planes del ayuntamiento. Estos planes que abordaban temas como la educación, la sanidad, o la calidad de vida en general, fueron asistidos por profesionales y técnicos antifranquistas de todo tipo (arquitectos, abogados, sociólogos, etc.). De algún modo se podrían tomar como "planes estratégicos populares.

Las asociaciones de vecinos fueron el canal participativo por excelencia, no sólo entre los trabajadores de las barriadas de infravivienda y con graves problemas urbanísticos, sino también entre las clases medias progresistas y catalanistas que habitaban los barrios centrales de la ciudad como El Ensanche o Gracia. Los unos demandaban calidad de vida urbana, aderecho a la ciudad", y los otros un desarrollo urbano racional y respetuoso con el patrimonio histórico de la ciudad ${ }^{14}$. De este momento político y social surge un estilo asociativo que está basado en la reivindicación y que a menudo plantea la resolución de conflictos con la Administración o con particulares mediante el enfrentamiento. Este estilo reivindicativo coexiste y comparte redes sociales con los tejidos basados en la tradición asociativa catalana que, a su vez, conforma otro estilo menos reivindicativo. Con el tiempo ambos estilos van separándose hasta constituir formas distintas de relacionarse con la comunidad y con las instituciones locales.

En 1974 se creó la FAVB (Federación de Asociaciones de Vecinos de Barcelona), agrupando a todas las entidades vecinales de Barcelona. Una vez en democracia, el carácter del conflicto urbano cambió, aunque no desapareció. El movimiento asociativo jugó un papel determinante participando en la concepción del modelo de ciudad a través de reivindicaciones y movilizaciones, logrando obtener algunos espacios en las instituciones locales, que se fueron ensanchando con el proceso de descentralización. Es importante resaltar el peso del contexto político en el que todo esto tuvo lugar. Barcelona tenía en aquellos años una fuerte cultura de clase obrera y unas clases medias de talante progresista, lo que explica el hecho de que sea la única gran ciudad española que mantenga una mayoría de izquierdas en el gobierno local. Como en muchas de las grandes ciudades, en las primeras elecciones los partidos de izquierda lograron la mayoría, y, como en la mayoría de los ca- 
sos, la falta de cuadros y técnicos en los partidos para completar la nueva administración local democrática llevó a un proceso de cooptación y fichaje de nuevos funcionarios en el movimiento vecinal. La democratización de los ayuntamientos supuso en algunos casos la crisis para los movimientos sociales, puesto que no sólo se quedaban sin líderes, sino sin el contenido de algunas reivindicaciones, que fueron asumidas por las corporaciones locales.

A partir del reconocimiento del hecho asociativo como un derecho fundamental en 1978 con la promulgación de la Constitución, el mapa asociativo catalán crece significativamente (de 669 entidades en 1980 a 1779 en 1990). Desde entonces hasta hoy, en lo que a movimientos sociales ${ }^{16}$ se refiere, los temas de interés han ido cambiando y ampliándose (medioambiente, pacifismo, género, cultura, solidaridad, cooperación internacional), además de cuestiones de urbanismo y participación política. Muchas entidades tienen objetivos sectoriales, no sólo específi$\cos$. En algunos casos, como las cuestiones territoriales y urbanísticas, los objetivos sobrepasan el ámbito de barrio o distrito que pueda tener una entidad y son asumidas por el movimiento asociativo en general.

Aunque la orientación de la nueva administración local democrática estaba orientada hacia la cooperación con los ciudadanos, el conflicto con los movimientos sociales urbanos, y. especialmente con la FAVB continuó durante los ochenta, alrededor de cuestiones relacionadas con la calidad de vida urbana y más participación en los procesos de toma de decisiones. Pese a que el tejido asociativo en Cataluña creció en términos generales a partir de la. década de los ochenta, consolidando el capital social que se había ido gestando en el período anterior, la evolución asociativa tiene dos momentos. En la primera mitad de la década la crisis económica provoca un cierto retroceso de la participación cívica en los movimientos sociales urbanos. El crecimiento en términos numéricos corre a cargo de los nuevos movimientos sociales antes mencionados. Tendencia que continúa a lo largo de la segunda mitad de la década, con la crisis económica superada. Se ha intentado establecer una relación entre el ciclo económico y el ciclo asociativo, pero esta cuestión debe tratarse con cuidado ${ }^{17}$, ya que el ritmo de crecimiento de unas y de estancamiento de otras tiene más que ver con el agotamiento de los modelos asociativos basados en la reivindicación urbana, como los que antes hemos definidos como movimientos sociales urbanos. En cambio, el tejido asociativo que surge 'en torno a los nuevos temas está durante unos años creciendo hasta que toca techo a mediados de los noventa. En algunos casos, ambos tipos de movimiento se sustentan sobre el mismo capital social, en otros, nuevas formas de. capital social se generan entre determinados segmentos de la población, como es el caso de los jóvenes. Se podría decir que la paulatina introducción de nuevos temas e inquietudes va conformando un estilo asociativo distinto, menos movilizador y con unas relaciones más fluidas con la administración local.

Durante los años ochenta, la principal tendencia del Ayuntamiento de Barcelona, como el de los ayuntamientos de casi toda España, fue hacia una racionalización y monopolización en el diseño de políticas públicas ${ }^{18}$ de contenido general. Pese a que la cuestión de la participación se había planteado como la "cuestión clave" para desarrollar la gestión local en un principio, se acabó enfatizando la democratización de la vida local a través de los mecanismos de representación tradicionales. La estrategia para desarrollar un «estado local" del bienestar, partiendo prácticamente de cero, fue la de conseguir un cierto grado de burocratización que de alguna manera minimizaba las expectativas de influir en el diseño e implementación de políticas, especialmente en lo que hacia referencia a las cuestiones de consumo colectivo. Si bien este ensayo se centra exclusivamente en la participación ciudadana en el ámbito territorial, es de destacar la creación a partir de 1989 del Consejo Municipal de Bienestar Social, dependiente del Ámbito de Bienestar Social, como principal mecanismo de participación sectorial en Barcelona y que reúne a todos los sectores de la sociedad civil en un consejo consultivo para el diseño de políticas públicas.

Los Juegos Olímpicos significaron un cambio importante tanto en los contenidos de las reivindicaciones de calidad de vida urbana como en la actitud del gobierno local hacia la cuestión de la participación. Por un lado, las demandas sobre cuestiones de consumo colectivo se redujeron por las fuertes inversiones en infraestructuras y equipamientos que mejoraron notablemente el entorno urbano. Por otro lado, desde la administración local se enfatizaron nuevos tipos de participación que suponían nuevas formas de relación entre actores; desde el modelo de participación del ciudadano como individuo que se encarna en la figura del "voluntario olímpico", hasta la aparición de entidades asociativas prestadoras de servicios y financiándose a sí mismas. Podemos decir que en este período se consolida la aparición de nuevos estilos asociativos con respecto a los setenta y primeros ochenta, lo que va a influir determinantemente en las relaciones entre actores a nivel sectorial y territorial. Son estilos mas dinámicos e integradores que aprovechan los huecos que cierto grado de desregulación administrativa deja en el ámbito local.

Pese a que a la ciudad se la lavó la cara con la operación olímpica, lógicamente las inversiones no afectaron por igual a todos los barrios, especialmente a aquellos más alejados del "epicentro" de los actos, y que, por otro lado, eran los que más carencias presentaban, pues habían surgido en los cincuenta y sesenta como consecuencia de la inmigración interior. Pese a que para entonces la movilización y el enfrentamiento como forma de resolución de conflictos había decaído mucho, en determinados barrios se siguieron produciendo como medio para 
obtener reivindicaciones sobre cuestiones de consumo colectivo. La estructura del capital social y los estilos asociativos reivindicativos en esas áreas habitadas por inmigrantes de otros puntos de España se siguió basando más en la movilización colectiva para alcanzar sus objetivos, en comparación con otros tejidos asociativos vinculados a la cultura obrera catalana tradicional, donde se hace uso de un estilo asociativo más basado en el consenso y la negociación. Una consecuencia importante de esto es que el tipo de relaciones entre los políticos locales y sublocales y los líderes de las entidades son distintos en cada caso.

En aquellas áreas donde se asientan tejidos asociativos, que podríamos llamar tradicionales ${ }^{19}$, el estilo asociativo se define por el uso del consenso como principal vehículo de resolución de conflicto y porque generalmente las relaciones con los políticos son fluidas. El uso de recursos informales de negociación es muy habitual, asi como la existencia de vínculos comunes asociativos (ateneos, esbarts, collas, etc.) entre los técnicos y políticos municipales y los líderes de las asociaciones. Estas entidades generalmente muestran niveles de democracia interna y de renovación más altas que las anteriormente descritas. A menudo constituyen aentidades paraguas": es decir, que un núcleo asociativo inicial, tradicional y/o reivindicativo acaba congregando a su alrededor otros grupos diversos (medioambiente, género, tercera edad, extranjeros, etc.).

Las diferencias entre unos y otros tipos de movimientos no son tan grandes como para afirmar que se sustentan sobre distintos tipos de capital social sino que conforman estilos asociativos diferentes. Esto no sólo se refiere a los objetivos, sino a las pautas organizativas y a la interacción con las instituciones locales. Estas diferencias influyen asimismo en el acceso a los mecanismos de participación y al uso de mecanismos informales de negociación. Estas cuestiones contribuyen a explicar los diferentes resultados del proceso de descentralización en términos de mecanismos de participación. Los diferentes estilos sí que se dan en uno y otro tipo capital social, según las objeciones de Boix y POSNer a Putnam, en función de que genere un tipo de bien público o privado.

\section{Descentralización de la administración local en Barcelona}

En la siguiente sección se va a analizar la evolución del proceso de descentralización del Ayuntamiento de Barcelona desde el punto de vista político y administrativo en relación a la participación ciudadana.

A grandes rasgos el proceso se puede resumir en torno a una serie de cuestiones: a) división territorial, b) dotar de competencias a los distritos, c) reforma política y administrativa, d) representación y participación política. La descentralización tiene lugar en tres etapas.

a) En la primera se define y consolida el nuevo modelo de gobierno local democrático. Entre 1979, con las primeras elecciones democráticas locales, y 1985, se establecen las bases para la descentralización a través de dos hechos fundamentales: la división de la ciudad en los diez distritos actuales y las Normas Reguladoras de Organización de los Distritos y de Participación Ciudadana (1986).

El diseño de los distritos supuso una considerable participación de la FAVB. El hecho de que los nuevos distritos se establecieran después de consultar con la FAVB es importante en un contexto tan delicado como el de la transición. Los diez distritos son el resultado de un proceso de consulta popular, y como consecuencia, los límites de los barrios que se delimitaron dentro de un Distrito eran los que definieron los miembros de cada asociación de vecinos (AAVV). Esto otorgó al movimiento vecinal una cierta autonomía espacial esencial para reforzar las identidades locales y ejercer una presencia más articulada tanto en la esfera local como sublocal de la administración. En términos de descentralización, el resultado más significativo fue que los distritos aparecen como unidad de gestión y los barrios como unidad de participación.

Las normas de participación y organización de los distritos se aprobaron en $1986^{20}$ y dieron a los distritos cierto grado de autonomía, incluida la posibilidad de desarrollar instrumentos de participación ciudadana. La descentralización tuvo dimensiones administrativas y políticas. Desde la dimensión administrativa de la ciudad, a los distritos les dieron el poder de decisión, gestión y control sobre diversas áreas ${ }^{21}$ y tres órganos de gobierno: el presidente del Consejo del Distrito, el Consejo del Distrito (15 miembros) y la Comisión de Gobierno. El aspecto político de la descentralización está relacionado con el funcionamiento de estos órganos. El presidente del distrito es elegido por el partido más votado en cada distrito, y los concejales mediante listas cerradas. Como en otros aspectos de la cultura política catalana, este sistema está regido por el consenso. El hecho de que el partido más votado en un distrito elija al presidente no es bajo prescripción legal, es el fruto de un pacto entre caballeros entre la coalición en el gobierno, y la oposición, fundamentalmente fuerzas nacionalistas. En siete de los diez distritos, PSC-IC durante las últimas cinco elecciones ha mantenido una mayoría en general holgada. El que se estableciera esta regla no escrita implica hasta cierto punto la cesión de una porción de poder territorial a la oposición en aquellos distritos donde son votados mayoritariamente partidos de la oposición. La figura del presidente del distrito supone un paso cualitativo en el camino hacia la descentralización. Cada presidente puede desarrollar una gestión coherente con respecto a sus votantes en su propio distrito. Aunque este aspecto supone un avance 
en democracia local con respecto a otras ciudades españolas, como por ejemplo Madrid, lo verdaderamente democrático sería que los presidentes fueran elegidos directamente por los votantes, no por los representantes. Esta opción no es posible ahora merced a las normativa vigente a nivel nacional. Sólo mediante la aprobación definitiva de la Carta Municipal se podría introducir una modificación en este sentido. La Carta Municipal, actualmente pendiente de ratificación, es una especie de "Constitución de las ciudades" que confiere competencias especiales al gobierno municipal en materias de urbanismo, bienestar social, educación y justicia.

Las funciones políticas del Distrito son elaborar y gestionar el presupuesto anual, establecer las necesidades del distrito e informar y aprobar aquellas partes de planes municipales y programas que afecten a los distritos. Para ello, aparte de la Comisión de Gobierno y del Consejo de Distrito, existen Consejos y Comisiones sectoriales, que son los mecanismos de participación más importantes a nivel de distrito.

El papel de las comisiones es seguir la implementación 'día a día' de las políticas del Distrito en un determinado tema. Los ciudadanos pueden controlar de alguna manera que la actuación prevista es la correcta. En los consejos se discuten las líneas principales de temas específicos. En este caso, la participación se traduce en la posibilidad de influir en el diseño y evaluación de las políticas públicas del Distrito. Otros mecanismos de participación de menor importancia, por la escasa capacidad de influencia del ciudadano, se concretan en distintos modelos de forums de discusión, que están orientados a promover el consenso entre las partes.

En términos generales, podemos decir que todo el proceso de descentralización en su etapa inicial estaba orientado al consenso con diferentes actores políticos. Una Comisión Ciudadana se estableció para asesorar el proceso. Estaba formada por representantes del gobierno regional, ciudadanos singulares y representantes de la sociedad civil, especialmente el movimiento vecinal. Tanto las normas de descentralización como las de participación se sometieron a un proceso de información y consulta. Las expectativas para los movimientos sociales urbanos eran más elevadas de lo que encontraron en términos de participación en la organización política y administrativa de la ciudad. El carácter estrictamente consultivo en el diseño e implementación de políticas se debía a la prioridad que se dio a criterios técnicos y de racionalización.

b) La segunda fase, entre 1986 y 1987, consiste fundamentalmente en el desarrollo del proceso de transferencia de competencias a los Distritos, gestionados por la Comisión Municipal de Descentralización y Participación Ciudadana. El resultado fue una administración local con dos niveles de desarrollo en la cuestión de la descentralización: completamente descentralizada desde el punto de vista administrativo, con un fuerte impulso de la gestión, y con un nivel relativo de descentralización conseguido desde el punto de vista político que situaba a' los habitantes de Barcelona en el plano de los usuarios en lo que a provisión de servicios se refiere.

c) Finalmente, a partir de 1988 , los distritos han recibido todas sus competencias y han comenzado a funcionar como unidades descentralizadas. El desarrollo completo del proceso va más allá de la transferencia y la delegación e incluye una reorganización de la estructura administrativa a través de innovaciones en la gestión ${ }^{22}$, que se desarrollan con distinto ritmo en cada Distrito.

Los valores sobre los que se basan los mecanismos de participación están basados en la información pública" y en la "comunicación con la ciudadanía ${ }^{23}$. De los cuatro ámbitos de decisión en que se puede descomponer cualquier proceso de toma de decisiones en una organización (estratégico, táctico, operativo ${ }^{24}$ e informativo), podemos afirmar que tanto los mecanismos de participación territorial como los valores sobre los que descansan se encontrarían entre los dos últimos, salvo en casos muy específicos de políticas a nivel micro, de barrio, donde puede haber alguna posibilidad de influir en el ámbito táctico. Los mecanismos más importantes a nivel de Distrito, los Consejos y Comisiones sectoriales, dotan en distinta medida de voz al ciudadano. El grado de efectividad de esa voz depende de la capacidad de consenso y de presión que tengan los actores entre sí.

Desde principios de los años noventa se ha venido consolidando una tendencia en la que la participación en el ámbito del distrito ha surgido de iniciativas de abajo-arriba y no tanto desde el uso de los instrumentos de participación. Han ido surgiendo nuevas formas de coordinación y coproducción entre entidades y Distrito, en las que el principal papel desempeñado hasta entonces por los movimientos sociales urbanos, el reivindicativo, pasa a convertirse en proveedor de servicios a la comunidad. En este contexto el acceso a la participación transciende el ámbito territorial ${ }^{25}$ y se sitúa sobre todo al alcance potencial de aquellas entidades más activas y capaces de modernizarse. El ámbito del bienestar social y de la gestión de equipamientos es donde mejor se manifiesta esta tendencia, cuyo principal resultado es la generación de vínculos de confianza y cooperación entre los actores. Un excelente ejemplo es el caso del Secretariat d'Entitats, en el que 191 asociaciones, clubes y entidades de todo tipo, agrupando a unos 35.000 socios (de un total de 167.000 habitantes en el distrito). El Secretariat gestiona un polideportivo y un centro cívico. La gestión del polideportivo se obtuvo mediante concurso público en competencia con empresas privadas y se gestiona con criterios empresariales, pero no de máximo beneficio-mínimo costo, sino máxima calidad-mínimo costo. Con los beneficios que se gene- 
ran se financia el centro cívico y una serie de servicios comunes para las entidades.

Estas nuevas tendencias aún no son asumidas por algunas redes asociativas que todavía practican el aviejo estilo" reivindicativo de resolución de conflicto mediante el enfrentamiento, si bien también es cierto que en los ámbitos territoriales de estas entidades en muchos casos persisten también los aviejos problemas" de la Barcelona preolímpica e incluso de la "paleolímpica", como por ejemplo déficit en infraestructuras, servicios y dotaciones.

En términos generales se puede decir que, debido a la estabilidad política en el gobierno local durante los últimos diecinueve años, una actitud abierta hacia la participación y un sólido capital cultural que se alimenta de las culturas políticas y asociativas locales, se han desarrollado en gran medida unas sólidas redes sociales de muy variada índole. Su capacidad de influir en el proceso de toma de decisiones a nivel de distrito varía territorialmente en función de los estilos del capital social y de la organización formal de los mecanismos de participación a nivel sublocal.

\section{El mapa asociativo de Barcelona en relación al tipo de capital social}

La medición del capital social y de la participación en el tejido asociativo ha sido siempre problemática. PuTnam resolvió la primera cuestión mediante el indicador ya descrito de la comunidad cívica que se construye con cuatro componentes: el voto preferente ${ }^{25}$, la participación electoral, la lectura de periódicos y la presencia de asociaciones culturales y deportivas. En cuanto a la segunda cuestión, existen varios indicadores que se pueden usar para evaluar el peso real de las redes asociativas: su grado de actividad, sus objetivos, la afiliación o su densidad por número de habitantes. Cada uno muestra virtudes e inconvenientes. Sobre un universo de más de dos mil quinientas entidades resultaría imposible establecer de manera fiable los grados de actividad de las entidades. La afiliación, como en otros ámbitos asociativos en España (sindicatos, partidos, etc.), está dejando de ser significativa con respecto a la capacidad de movilización. En el caso del tejido asociativo hay gran cantidad de personas que toman parte en las actividades de las entidades sin ser socios, y, al revés, puede haber entidades con varios miles de asociados, al corriente o no de sus cuotas correspondientes, que son mantenidas vivas en el dia a día por pocas docenas de miembros. Por lo general, la información sobre afiliación es irregular y de poca calidad.
En el caso que nos ocupa, el tejido asociativo de Barcelona va a ser medido mediante una tipologización de sus actividades y la densidad de la red, en relación al número de habitantes. En otras palabras, se va a utilizar uno de los componentes que utiliza Putnam en el indicador de comunidad cívica, pero apasados por el tamiz que proponen Borx y POSNER: clasificando las entidades según produzcan bienes públicos y privados. El resto de propuestas se convierten en imposibles de realizar a partir de un simple censo asociativo.

\section{El mapa}

Se han establecido dos formas principales de capital social: el que produce bienes públicos $(\mathrm{Pb})$ y el que produce bienes privados ( $\mathrm{Pr}$ ). Cada una de estas categorías ha sido dividida a su vez en varios tipos de sub-categorias dependiendo del tipo de entidad que produce el bien en cuestión ${ }^{26}$. La cuestión territorial ha sido abordada desde una doble perspectiva. En primer lugar, se ha hecho una distinción entre aquellas asociaciones cuya actividad está relacionada principalmente con la ciudad de Barcelona y sus distritos (T), y con aquella cuya actividad está relacionada con una unidad territorial mayor (eT), como por ejemplo Cataluña o España. En segundo lugar, se toman los distritos de Barcelona como unidad territorial comparativa con una población de $1.508 .805^{27}$. En esta ocasión se ha optado por hacer una comparación entre distritos en términos de capital social y tejido asociativo, y no tanto hacer una radiografia detallada del capital social en cada distrito.

El capital social de Barcelona muestra a primera vista un alto número de asociaciones de todo tipo (2527) para una ciudad de un millón y medio de habitantes. Esta cifra incluye tanto a aquellas asociaciones que operan solamente en Barcelona (a nivel de ciudad, distrito y barrio) y aquellas otras que desarrollan su actividad en un ámbito territorial más amplio. Aunque Barcelona es la segunda ciudad española ${ }^{28}$ y la capital de una Comunidad Autónoma con un importante capital social y sólidas tradiciones asociativas, el peso real de este factor no resulta tan significativo en términos reales como podría esperarse, es decir, de todas las entidades censadas en Barcelona sólo el $16,7 \%{ }^{29}$ (eT) tienen una actividad a nivel nacional o regional, y no local. El grupo más importante de entidades dentro de esta categoría se dedica a grandes temas generales como la nueva cultura política (NCP) (23,5\%), difusión científica (19,5\%), y a otras actividades grupales como servicios asistenciales por entidades laicas $(9,4 \%)$ y cultura y educación $(11,4 \%)$. Tres de los cuatro son productores de bienes públicos, lo que implica que su actividad es potencialmente beneficiosa para toda la sociedad. La importancia del mutualismo anteriormente reseñada da cuenta del alto número de entidades de este tipo que era aún mayor, antes de ser absorbidos por la Generalitat a finales de los años ochenta. Un tejido asociativo con intereses generalistas 
implica un capital social fuerte en solidaridad y reciprocidad y una comunidad abierta a la filantropía. Como apoyo a este dato cabe destacar que entre 1983 y 1995 se crearon 629 fundaciones en Cataluña ${ }^{30}$. La mayoría de las entidades de NCP guardan relación con el género, la economía social, medioambiente y solidaridad con el tercer mundo.

En el ámbito que hemos denominado extraterritorial, las asociaciones productoras de bienes privados no tienen tanta importancia, puesto que su actividad suele estar vinculada a medianas y pequeñas interacciones grupales, excepto para las cuestiones culturales y educativas.

Para el propósito de esta investigación es más significativo el estudio de entidades cuyo ámbito es el municipio de Barcelona, en sus distritos y sus barrios (T) como aparecen reseñados en la tabla 1. En Barcelona hay un mayor número de entidades que producen bienes de tipo privado que de tipo público: $44,3 \%$ y $52 \%$, respectivamente (otros To, 3,32\%). Estas cifras dan cuenta del contexto anteriormente descrito de un alto grado de integración de las redes sociales locales, centradas alrededor de la interacción en grupos relativamente pequeños, con fuertes vínculos culturales y de coordinación que generan un capital social orientado a la provisión de bienes privados para la comunidad. Los tres principales tipos de redes sociales que muestran una presencia más alta son: Cultura y Educación (Pr2), Ocio y Cultura Popular (pr1) y Cultura Catalana (Pr5b).

En Barcelona hay un fuerte tejido asociativo de entidades relacionadas con la cultura, principalmente la música y el teatro, así como la educación. Pese a haber sido excluidas las APAS, por su carácter obligatorio, existe una importante presencia de entidades de carácter pedagógico o vinculados a la enseñanza. El carácter territorial de un buen número de ellas refuerza la idea de que es en ámbitos micro y mesolocales en los que se desarrolla una buena parte del capital social en la ciudad.

Ocio y Cultura popular y Cultura Catalana son importantes a la hora de detectar el grado de densidad y calidad del capital social de los distritos, porque contienen algunos de los elementos clave mencionados anteriormente para constituir una identidad colectiva: creencias, identidad común e inversión emocional. Bajo la categoría de Ocio se han agrupado algunas de las formas más características del asociacionismo en Cataluña, como los esplais, que son una especie de clubes donde los niños y las niñas en edad escolar pasan algunas horas a la semana después del colegio, realizando actividades didácticas y de entretenimiento. Principalmente están llevadas por jóvenes voluntarios. Estas actividades son el primer eslabón de una cadena asociativa que socializa al individuo en un medio de confianza y reciprocidad. Otras redes dentro del ámbito del ocio son los grupos excursionistas y los de boy-scouts mencionados anteriormente. El asociacionismo cultural específicamente catalán está compuesto por un conjunto de actividades de cultura popular que van desde los coros de dife- rentes tipos (corales, coros de Clavé, etc.) y danzas tradicioniles, hasta los ateneos y las collas. Una colla es un grupo de gente que desarrollan una actividad artística o lúdica juntos de manera regular. Las hay de diversos tipos: de diables, gigants o castellers, entre otras. Especialmente en las dos primeras los componentes son gente joven. Los castellers son probablemente la mejor metáfora de la cooperación y la confianza en la sociedad catalana. El objetivo es construir una torre humana. Las collas, que van desde unas decenas hasta unos cientos de miembros, construyen torres en las que sólo se elevan unos pocos miembros del grupo, pero soportados por una sólida base formada por los brazos y hombros del resto, de todas las edades.

Las asociaciones regionales son relevantes para entender las redes sociales generadas por las personas que tuvieron que emigrar desde otras regiones españolas, principalmente entre 1950 y 1970. Las casas regionales son asociaciones o federaciones cuyas actividades están centradas alrededor de diferentes regiones o provincias de España, promoviendo actividades sociales y culturales y festivales. Las casas se han convertido en importantes actores sociales y, hasta cierto punto de vista, politicos, puesto que su influencia electoral es considerada estratégica por los gobiernos municipales del área metropolitana (socialdemócratas) como por el autonómico (derecha nacionalista moderada). Las más importantes representan a las regiones de origen de la mayoría de la población que se trasladó a Barcelona: Extremadura y Andalucía. Las Casas y entidades afines andaluzas de Barcelona y su área metropolitana congregan cada año a mas de un millón de personas en la Feria de Abril, en lo que probablemente es la mayor concentración periódica en todo el Estado. La distribución de estas entidades no sigue un esquema estrictamente territorial. Parecería lógico que se ubicaran en los barrios donde la gente venida de otras regiones habita. En cambio, se concentran mayoritariamente en el centro de la ciudad.

Finalmente, es destacable también notar que la existencia de asociaciones culturales extranjeras $(2,8 \%)^{31}$, vinculadas en su mayoría a las comunidades de trabajadores de origen extranjero de países del Sur (Asia, Magreb, África, Latinoamérica) que se concentran el centro donde muchas de estas comunidades se han ido asentando debido a la caída del precio del suelo y de los alquileres.

Las entidades que producen bienes públicos más numerosos son las de consumo colectivo (transportes, equipamientos, etc.) y las de nueva cultura política (NCP), siendo las asociaciones de vecinos las más importantes de entre las primeras. En muchos casos ambos tipos comparten locales y militancia. Muchas de las entidades de NPC se han formado alrededor de núcleos asociativos ya consolidados, impulsados por miembros jóvenes que ya no se sienten tan identificados con las cuestiones de consumo colectivo tradicionales. Por otro lado, la simbiosis en- 
tre ambos tipos de entidades ha devuelto contenido y protagonismo a las entidades más antiguas como 'asociaciones paraguas' en las que a partir de un núcleo original, generalmente reivindicativo, van apareciendo otros de distinto tipo, desde $\mathrm{NCP}$ hasta culturales de todo tipo. Esto es el caso para algunas cle las antiguas entidades reivindicativas de la periferia del municipio, con una fuerte tradición de izquierdas donde la aparición de estos nuevos núcleos es frecuente. La vinculación entre ambos tipos es tal, según se desprende de la información cualitativa disponible, que podría justificar el elevado aumento de pertenencia a entidades vecinales que registra la Encuesta de la Región Metropolitana de Barcelona ${ }^{32}$ entre 1985 (3,3\%) y 1995 $(8,6 \%)$ al identificarse una entidad con la otra.

Las entidades asistenciales laicas entre las que se encuentran aquellas de asistencia a enfermos, a ancianos y los grupos de ayuda mutua representan el $7,7 \%$ del total del entidades que ofrecen bienes de tipo público. Especialmente estas últimas son una muestra de la importancia del capital social a la hora de generar un tejido asociativo. Los GAM son asociaciones de afectados por enfermedades (SIDA, cáncer, alcoholismo, padres de pacientes con espina bífida) o circunstancias sociales diversas (malos tratos, parientes en prisión) que se coordinan para cooperar en la mejora de sus condiciones de vida con respecto a su problema específico.

El resto de entidades asistenciales laicas juegan un papel importante en la provisión de determinados servicios de bienestar social y se han ido integrando a lo largo de la última década a los mecanismos de participación no territoriales del Ayuntamiento de Barcelona ${ }^{33}$ en el proceso descrito anteriormente.

Finalmente, cabe reseñar el hecho de que un 3,6\%, es decir, 77 , de las entidades que ofrecen bienes públicos para Barcelona ciudad sean fundaciones dedicadas a la difusión científica y cultural. Este hecho se explica por la presencia de una burguesía industrial y comercial con una importante tradición filantrópica e intelectual.

\section{El capital social en los distritos}

Barcelona se compone de diez distritos que muestran una distribución desigual en el número de asociaciones proporcionando bienes públicos y privados. El tamaño de los mismos y su número de habitantes introducen un sesgo importante que se puede compensar calculando la tasa de habitantes por asociación ${ }^{34}$.

En la tabla 5 podemos ver que la población en los distritos varía considerablemente, como también lo hacen las características de los mismos. A continuación vamos a esbozar muy brevemente los rasgos mas importantes de cada uno ${ }^{35}$. El distrito 1, Ciutat Vella, coincide con el casco histórico de la ciudad y ha sido habitado durante los últimos décadas por clases trabajadoras y una pequeña burguesía comercial y burocrática en decadencia. Es el distrito donde la tasa de población de origen extranjero es más alta (en torno al 10\%). El distrito 2, Eixample, es el más grande de Barcelona. Es el resultado del Plan Cerdá, diseñado a mediados del siglo XIX y sólo completado hace unas décadas. Representa alrededor de un quinto de la población de la ciudad, y está habitado principalmente por clases medias y altas. Los siete distritos restantes son el resultado de la expansión de la ciudad a principio de siglo hacia los municipios vecinos que a lo largo de la primera mitad de siglo pasan a formar parte de la ciudad. Los distritos 3, 7, 9 y 10 (SantsMontjuich, Horta-Guinardó, Sant Andreu y Sant Martí) se convirtieron en barrios obreros a partir de 1900 con una fuerte cultura de clase catalanista. A partir de los años cincuenta, estas barriadas recibieron un gran número de inmigrantes de otras partes de España, lo que generó un crecimiento urbano desordenado con unas condiciones de calidad de vida ínfimas. La construcción de pisos baratos de protección oficial en los cincuenta y las progresivas promociones de vivienda social y privada de clase media han ido configurando la fisonomía de estos barrios que fueron sustituyendo a las barriadas de autoconstrucción, conviviendo con los núcleos rurales originales y los industriales. Gracia, el distrito 6, fue el primer municipio que se anexionó a Barcelona y en él conviven hoy clases medias, con segmentos envejecidos y empobrecidos y jóvenes profesionales y estudiantes. El Distrito 8, Nou Barris, se desarrolló casi totalmente a partir de los cincuenta en el mismo contexto antes descrito y se caracteriza por ser el que presenta un mayor déficit de infraestructuras y servicios. Los distritos 4 y 5 , Les Corts y Sant Gervasi, comparten una población de clases medias y altas, en torno a sendos antiguos núcleos rurales, en los que subsisten pequeñas zonas con estratos bajos.

Como muestran las tablas 2 y 3 , hay una cierta polarización respecto al número de habitantes por asociación (I), especialmente entre 1 y 7 . Desde un punto de vista general $(\mathrm{T}+\mathrm{eT})$, la media es relativamente baja ( $\mathrm{I}=597,1)$, es decir, que todo parece indicar que la densidad asociativa en Barcelona es alta. La concentración de las I más bajas en los distritos centrales $(1,2$ y 6$)$ se explica, aparte de por su riqueza asociativa, también por la atracción que estas zonas ejercen para determinado tipo de entidades como ONGs, fundaciones y en general aquellas cuyo ámbito de actividad no se circunscribe solamente al ámbito local (T), sino también a nivel regional y nacional (Et). En el caso del distrito 5 los bajos índices de I se deben a la demanda por parte de entidades con recursos, como fundaciones, que demandan sedes representativas. Los distritos 7 y 8 muestran las I más altas. Los distritos 9 y 10 están formados principalmente por barrios tradicionalmente obreros y comparten redes asociativas densas, como también ocurre en 3 y 6. El distrito 7 es el que más baja densidad asociativa muestra, triplicando la media. 
Si consideramos sólo las entidades de ámbito local (es decir, $\sin \mathrm{eT}$ ), la diferencia es pequeña. Sigue habiendo una concentración en el segmento de los 500-1000 habitantes por asociación de la mayoría de los distritos.

Cuando diferenciamos según el tipo de bien que ofrecen las entidades (tabla 2), encontramos que la distribución del capital social varía territorialmente. Lógicamente, las densidades se rebajan para Tpb y Tpr de manera generalizada, pero, lo que es más interesante, la distribución territorial se modifica de manera importante. Para las entidades que producen bienes públicos, I se sitúa en 1618,9. La tendencia de esta forma de capital social es a concentrarse en 1,2 y 6 , los tres distritos que formaban Barcelona originalmente (ver tabla 1). Especialmente llamativo es el caso de 1, en la que la alta concentración de un tejido asociativo que ofrece bienes públicos de carácter asistencial laico y religioso se justifica por los bajos índices de calidad de vida de la mayoría de los barrios del distrito ${ }^{36}$. En general, se observa una tendencia a que la densidad asociativa decrezca en aquellos barrios con mayor densidad de población ${ }^{37}$ que coinciden con los que albergan una mayor población no oriunda de Cataluña $^{38}$. Esto no significa que este tipo de población se asocie menos, pero sí de otra manera. Como hemos indicado anteriormente, se puede hablar de un estilo asociativo más reivindicativo, en parte por un capital social distinto, en parte por unas condiciones urbanas específicas. La actividad del movimiento vecinal en distritos como el 8 , de los más ricos en vida asociativa, el 9 y el 7, especialmente en los barrios ade aluvión", fue intensísima en los setenta y ochenta y dada la gran densidad de población las asociaciones de vecinos a menudo agrupaban a varios miles de asociados o simpatizantes, puesto que las demandas en cuestiones de consumo colectivo eran muy movilizadoras. Para una parte de estas entidades en la actualidad se ha reducido mucho su actividad a cuestiones muy puntuales. Estas cuestiones, no obstante, pueden revitalizar el papel de las entidades vecinales como prestadoras de servicios de consumo colectivo ante cuestiones puntuales, como es la actual campaña del recibo del agua en varios distritos de la ciudad ${ }^{39}$.

En lo que a bienes privados se refiere la densidad es más alta $(I=1370,4)$ debido a la presencia de un importante número de entidades deportivas y de ocio, y la incidencia del capital social que se genera en torno a las entidades de cultura catalana. Éste se refleja en las áreas donde hay núcleos importantes de clase trabajadora de origen catalán $(3,9$ y 10$)$, donde se concentran densidades entre 1000 y 1500 habitantes por asociación (Ver tabla 2).

Hasta aquí podemos concluir que en términos absolutos la densidad asociativa es bastante alta, es decir, hay un número relativamente bajo de habitantes por asociación y que la tendencia de las entidades radicadas en Barcelona es ofrecer bienes públicos.
Se puede afirmar que la sociedad catalana y la barcelonesa en concreto disfruta de un fuerte capital social. Las redes sociales que se sustentan sobre este capital social están alimentadas por la cooperación y la confianza. Al analizar detenidamente el capital social circunscrito estrictamente al ámbito local y sublocal, encontramos que, pese a que sigue siendo muy importante, se invierte la tendencia inicial. Es un capital social que genera más bienes privados que públicos, debido entre otros factores a que al discriminar a las entidades extraterritoriales ganan peso las actividades culturales y tradicionales, especialmente las que giran en torno a la cultura catalana. Se puede decir que hay pautas o estilos asociativos distintos basados en las distintas formas de organizarse y de resolución de conflictos que se pueden explicar, por un lado, por el capital social específico de los habitantes de cada barrio y, por otro, por la existencia de reivindicaciones de consumo colectivo aun no resueltas.

\section{Mecanismos de participación: imedios de cooperación?}

En la siguiente sección vamos a ver cómo la existencia de un gobierno local descentralizado y unos mecanismos de participación a nivel de los Distritos no van a implicar necesariamente esquemas de participación homogéneos. Las características del capital social en cada distrito van a dar cuenta de la existencia de medios de participación informales que pueden ser alternativos a los mecanismos formales y con otros grados de eficacia.

Dos indicadores de los efectos de la descentralización en la calidad de la participación ciudadana son los tipos de mecanismos desarrollados y su grado de formalización.

Los mecanismos de participación en los Distritos, fundamentalmente los Consejos y las Comisiones, muestran distintos grados de presencia en términos sectoriales (tabla 4). Por un lado, hay algunas cuestiones que generan más interés entre la ciudadanía a la hora de participar en la discusión y diseño de políticas públicas y otras iniciativas en los Distritos ${ }^{40}$. Esas cuestiones son las que tienen que ver con beneficios personales o privados para los ciudadanos (deportes, centros cívicos, educación) y aquellos que conciemen a grupos específicos (tercera edad, juventud, mujeres). Por otro lado, hay menos demandas de participación en cuestiones de consumo colectivo (urbanismo, seguridad y cultura). Es importante resaltar que hay más Consejos que Comisiones y que éstos están presentes en aquellas áreas donde hay una demanda mayor de participación. Como antes 
hemos visto, el Consell es un espacio de opinión desde el que hipotéticamente se puede incidir en las líneas de actuación en torno a un tema específico, mientras que la Comisión permite a los ciudadanos involucrarse en el día a día de las políticas en el distrito. En aquellas áreas donde hay demanda de instrumentos de participación es más habitual que se instaure un Consejo, que al no abordar cuestiones de implementación, su capacidad para participar es menor. La razón podría estar en la evitación del conflicto por parte de las autoridades. La justificación oficial podría ser la falta de cualificación técnica de los ciudadanos que ralentizaría el proceso de implementación de las políticas, pero teniendo en cuenta las experiencias de cogestión de equipamientos de distrito esto no siempre parece razonable como argumento.

El grado de formalización de un instrumento de participación depende del grado de planificación y del acceso de los ciudadanos a él (tabla 5). Hay varios grados de planificación con los que las Comisiones y Consejos se pueden organizar. En el caso de los Distritos de Barcelona el aspecto formal del mecanismo de participación, es decir, la planificación es mediaalta, pero sin embargo su aspecto real, el acceso de los ciudadanos y entidades al mecanismo es media-baja. La asistencia en general también es baja ${ }^{41}$.

Repasando cada distrito podemos establecer que en algunos casos los mecanismos de participación tienen efectos distintos para la participación teniendo en cuenta el tipo de relación que se ha encontrado entre los actores ciudadanos e institucionales ${ }^{42}$.

En el distrito 1, Ciutat Vella, un distrito con un capital social muy desarrollado, y la densidad asociativa más alta de toda la ciudad, pese a que la formalización de los mecanismos es baja y las relaciones regulares, la asistencia es alta. La variedad de intereses de los actores ciudadanos (asociaciones de vecinos, de comerciantes, de trabajadores de origen extranjero) y las problemáticas específicas del distrito (pobreza, fragmentación social, delincuencia, vivienda), hace que la participación mediante los mecanismos institucionales sea la forma más eficaz de influir en las actuaciones municipales.

Eixample, el distrito 2, con un capital social de los más importantes de la ciudad (junto con 1,3 y 8), presenta un grado de formalización alto en los mecanismos de participación que se explica por la amplia presencia de clases medias, en especial de una pequeña burguesía comercial. No obstante, pese a que las relaciones son buenas, la asistencia es baja. Esto se explica en función de dos factores: el bajo nivel de conflicto en un barrio donde las problemáticas urbanas y sociales son muy moderadas, y por lo tanto las entidades cuyo objeto es la reivindicación de cuestiones de consumo colectivo no formulan demandas excesivamente reivindicativas. En segundo lugar, la importancia de los mecanismos de comunicación informales, el hilo directo con políticos y técnicos, que sustituye a los formales.

Sants-Montjuich es uno de los distritos con un capital social más intenso. La pujanza de un sector vecinal muy reivindicativo pero en muy buenas relaciones con el Distrito, que ha desarrollado formalmente los mecanismos de participación, explica el alto nivel de asistencia. A esto hay que añadir la existencia de una fortísima cohesión entre las entidades a través del Secretariat d'Entitats que agrupa a la práctica mayoría de ellas.

Tanto en 4 como 5 y 6, Les Corts, Sarriá y Gracia, se aprecia una baja formalización de los mecanismos con una asistencia también baja. En los tres casos las relaciones son más bien regulares. En 4 y 5 se da la presencia de unos sectores reivindicativos pequeños y con pocos canales de comunicación con el Distrito, y actitudes poco proclives a la participación por parte de los Distritos, ambos de CiU. En 6, un distrito con una presencia asociativa importante, pero en situación de regresión, y con una crisis política casi permanente desde mediados de los ochenta (la mayoría de izquierdas, es la más vulnerable de la ciudad) que aleja a la participación de las prioridades políticas en el distrito. En los tres la participación es poco significativa.

Horta-Guinardó es un ejemplo de fomento a la participación formal desde el Distrito, mediante un alto grado de formalización de los mecanismos, que genera, en un distrito con las densidades asociativas más bajas de la ciudad y unas relaciones entre actores buenas, una respuesta positiva a los mismos.

El caso de Nou Barris, 8, es sin duda singular, siendo uno de los distritos con un capital social más intenso y predominantemente reivindicativo y por definición con una demanda de participación más alta. Las relaciones entre el tejido asociativo (incluyendo la FAVB) y el Distrito han sido muy tensas, con lo que de alguna manera se puede pensar que con un nivel de formalización no muy alto se pretenda desincentivar la participación y el conflicto casi constante en que están sumidos los actores. Por otro lado, el estilo reivindicativo de una parte importante del movimiento vecinal y la problemática del distrito, aun no resuelta del todo, hacen que, al no existir apenas los cauces informales, sea imprescindible asistir a las convocatorias para influir en la medida de lo posible tanto en el diseño de las políticas como en su ejecución.

En los casos de San Andreu y Sant Martí, 9 y 10, respectivamente, los grados de formalización medios llevan a una bajas asistencias, pese a que las relaciones son buenas, algo tensas quizá en Sant Martí. En este caso la heterogeneidad de intereses y de actores, y la presencia en Sant Martí de fuertes divergencias entre asociaciones de vecinos hace que la participación sea 
baja, pese a existir problemáticas sobre todo sociales y urbanísticas aún sin resolver.

En general, podemos afirmar que los medios de participación informales pueden suponer una alternativa en aquellos distritos donde hay demandas de participación, pero los mecanismos disponibles no son utilizados o su uso no se facilita al máximo. Esto sólo ocurrirá donde los estilos asociativos y el talante del equipo del Distrito permitan que haya comunicación por cauces no formales. La opción de voz no se reduce a las Comisiones, Consejos o Audiencias, sino en la interacción cotidiana entre los actores en cualquier otro ámbito. Si no hay posibilidad de voz, ni formal ni informalmente, la opción es la salida. La mera existencia de mecanismos de participación no es condición suficiente para que se utilicen, las variables de formalización que pueden afectar a la accesibilidad de los ciudadanos $y$, por lo tanto, a la consecución de su objetivo, que no es otro que éstos influyan en el proceso de toma de decisiones en un ámbito de descentralización territorial. La voluntad política y la forma que el capital social tome en cada distrito son, pues, determinantes para explicar los resultados de la participación ciudadana en los distritos de Barcelona.

\section{Tablas}

\begin{tabular}{|c|c|c|c|c|c|c|c|c|c|c|c|c|c|}
\hline \multicolumn{14}{|c|}{ Tabla 1} \\
\hline \multicolumn{14}{|c|}{$\begin{array}{c}\text { Porcentaje de distribución del capital social } \\
\text { ( } \mathrm{T}=\text { Asociaciones cuyo ámbito de actuación es la ciudad de Barcelona) }\end{array}$} \\
\hline \multicolumn{2}{|l|}{ Distritos } & 1 & 2 & 3 & 4 & 5 & 6 & 7 & 8 & 9 & 10 & $\begin{array}{c}\text { Total } \\
\text { Distrito }\end{array}$ & $\begin{array}{l}\text { Tipos } \\
\text { cap.soc. }\end{array}$ \\
\hline Consumo Colectivo & Tpb1 & 16 & 10 & 16 & 3 & 7 & 11 & 2 & 14 & 6 & 15 & $100 \%$ & 15,3 \\
\hline Nueva Cultura Política & Tpb2 & 22 & 31 & 9 & 3 & 2 & 8 & 3 & 6 & 4 & 12 & $100 \%$ & 15 \\
\hline Organizaciones Religiosas & Tpb3 & 25 & 31 & 11 & 0 & 0 & 11 & 11 & 4 & 5 & 2 & $100 \%$ & 2,6 \\
\hline Asistenciales Laicas & $\mathrm{Tpb4}$ & 14 & 23 & 11 & 4 & 12 & 12 & 6 & 1 & 10 & 8 & $100 \%$ & 7,7 \\
\hline Cultura y Educación & $\mathrm{Tpr} 2$ & 22 & 19 & 9 & 6 & 8 & 9 & 4 & 5 & 7 & 11 & $100 \%$ & 20,6 \\
\hline Deportes & $\mathrm{Tpr} 3$ & 9 & 1 & 17 & 6 & 7 & 10 & 10 & 10 & 12 & 17 & $100 \%$ & 3,2 \\
\hline Entidades Confesionales & $\operatorname{Tpr} 14$ & 9 & 21 & 17 & 2 & 6 & 8 & 6 & 13 & 10 & 11 & $100 \%$ & 2,9 \\
\hline Regionales (no catalanas) & Tproa & 29 & 29 & 10 & 2 & 2 & 4 & 2 & 2 & 4 & 17 & $100 \%$ & 2,4 \\
\hline Cultura Catalana & Tprob & 18 & 13 & 10 & 3 & 4 & 16 & 10 & 6 & 7 & 14 & $100 \%$ & 8,9 \\
\hline Nacionalistas & $\operatorname{Tpr} 5 \mathrm{c}$ & 22 & 11 & 22 & 0 & 0 & 0 & 0 & 0 & 22 & 22 & $100 \%$ & 0,4 \\
\hline \multirow[t]{2}{*}{ Culturas Extranjeras } & Tprd & 15 & 40 & 10 & 2 & 3 & 3 & 5 & 8 & 10 & 3 & $100 \%$ & 2,8 \\
\hline & Total Tpr & 17 & 18 & 11 & 4 & 7 & 9 & 6 & 7 & 9 & 13 & $100 \%$ & 96,7 \\
\hline (Otras entidades) & To & & & & & & & & & & & & 3,3 \\
\hline
\end{tabular}

Fuente: Elaboración propia 


\begin{tabular}{|c|c|c|c|c|c|c|c|c|c|c|c|}
\hline \multirow{2}{*}{ Distritos (en miles) } & \multicolumn{9}{|c|}{ Tathe 2} & \multirow[b]{2}{*}{10} & \multirow[b]{2}{*}{ Total } \\
\hline & 1 & 2 & 3 & 4 & 5 & 6 & 7 & 8 & 9 & & \\
\hline No Habitantes & 83,8 & 248,7 & 167,3 & 81,8 & 129,5 & 115,7 & 169,8 & 170,8 & 135,5 & 205,3 & $1.505,8$ \\
\hline $\mathrm{Hab} / \mathrm{Asoc}$ Total & 178 & 431,9 & 363,5 & 889,8 & 608,3 & 509,9 & $1.587,2$ & 1.139 & 886,1 & 746,8 & 597,1 \\
\hline $\mathrm{Hab} / \mathrm{Asoc}$ (sin eT) & 223,5 & 586,7 & 697,5 & $1.169,5$ & 846,9 & 581,9 & 1.769 & $1.186,5$ & 916,1 & 805,5 & 717,5 \\
\hline $\mathrm{Hab} / \mathrm{Asoc} \mathrm{Tpb}$ & 484,6 & $1.219,5$ & $1.579,2$ & $2.822,9$ & 1.825 & 1.825 & $4.995,1$ & $2.476,1$ & $2.558,1$ & $1.993,8$ & $1.618,9$ \\
\hline $\mathrm{Hab} / \mathrm{AsOc} \mathrm{Tpr}$ & 445,9 & 1.289 & $1.382,5$ & $1.996,5$ & $1.661,2$ & $1.661,2$ & $2.739,2$ & $2.308,8$ & $1.446,2$ & $1.446,2$ & $1.370,4$ \\
\hline
\end{tabular}

Fuente: Elabonción propia

\begin{tabular}{|c|c|c|c|c|c|}
\hline [totervalos & S[at & $\begin{array}{l}\text { mable } \\
\text { ensichad A } \\
\text { de Bare }\end{array}$ & 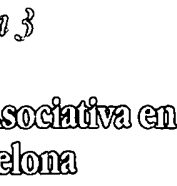 & D Los Distis? & ilos \\
\hline I-Hab/Assoc. & $<500$ & $500-1.000$ & $>1.000<1.500>$ & $>1.500<2.000$ & $>2.000$ \\
\hline Hab/Asoc Total & 1,2 & $3,4,5,6,9,10$ & 8 & 7 & \\
\hline $\mathrm{Hab} / \mathrm{Asoc}$ (sin eT) & 1 & $2,3,5,6,9,10$ & 4,8 & 7 & \\
\hline $\mathrm{Hab} / \mathrm{Asoc}$ & 1 & & 2,6 & $3,5,10$ & $4,7,8,9$ \\
\hline Hab/Asoc Total & 1 & & $2,3,6,9,10$ & 4,5 & 7,8 \\
\hline
\end{tabular}

Puente: Elaboración propia

\begin{tabular}{|c|c|c|c|}
\hline \multicolumn{4}{|c|}{ 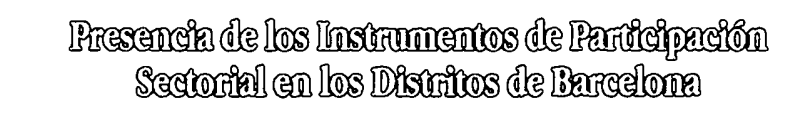 } \\
\hline Presencia & Baja & Media & Alta \\
\hline Consejo & " & & $\begin{array}{l}\text { Educación } \\
\text { Centros Civicos } \\
\text { Juventud } \\
\text { Género } \\
\end{array}$ \\
\hline Equilibrio & $\begin{array}{l}\text { Cuestiones Urbanas } \\
\text { Seguridad }\end{array}$ & & Deportes \\
\hline Comisiones & & $\begin{array}{l}\text { Cuestiones Urbanas } \\
\text { Seguridad }\end{array}$ & Tercera Edad \\
\hline
\end{tabular}

Fuente: Ayuntamiento de Barcelona

\section{Tionter 5 -}

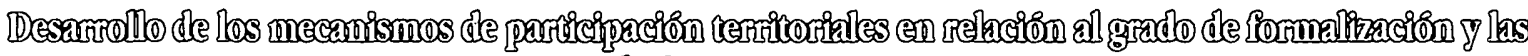
rielacoros emse actors

\begin{tabular}{cccc} 
Distrito & Grado formalización & Relación actores & Asistencia \\
\hline 1 & Bajo & Buena & Aita \\
2 & Alto & Buena & Baja \\
3 & Alto & Buena & Alta \\
4 & Bajo & Regular & Baja \\
5 & Bajo & Regular & Baja \\
6 & Bajo & Regular & Baja \\
7 & Alto & Buena & Alta \\
8 & Medio & Mala & Alta \\
9 & Medio & Buena & Baja \\
10 & Medio & Buena & Baja \\
\hline
\end{tabular}


- Universitat Pompeu Fabra, Departament de Ciències Polítiques i Socials.

1 VILLASAVTE, T. R. (1986) Comunidades locales. Madrid: IEAL.

: El proceso de producción del espacio urbano se puede entender como el resultado de la interacción entre los actores urbanos al conformar los usos y las formas de la ciudad a través de unas relaciones de dependencia mutua que a la vez son conflictivas. De la resolucićn de ese conflicto va a depender las distintas formas que tome el espacio urbano desde un punto de vista tanto físico como social y político. Koolman define urban govemance como las pautas emergentes de las actividades de gobierno de actores sociales, políticos y administrativos (Koolmav, J., (1993) Social-Political Governance: Introduction, en Koolmav (ed.): Modern Governance: New GovernmentSociety Interactions. London: Sage.

"Burvs, D., Hambleton, R. \& Hogcet, P. (1994). The politics of decentralization. Revitalizing local Democracy. London: McMillan. En inglés esta categorización se denomina 'the four C's': clients, customers, consumers and citizens'.

' HirschmanN, A.O. (1970) Exit, Voice and Loyalty. Cambridge, Mass: Harvard University Press.

Barbalet, J.M. (1988) Citizenship. Milton Keynes: Open University Press.

" Burns, Hambleton y Hogget, P. (1994). op. cit.

- Buchanam Y Tulock; (1967), Niskasen (1977) en Stoker, G. (1993). The Politics of Local Government. London: MacMillan.

s STOKER, G. (1993) op. cit.

"Woolcock, M. Social capital and economic development: toward a theoretical synthesis and policy fremework; in Theory and Society, vol. 27: 1998.

Ii' MelucCl, A. (1994) •Asumir un compromiso: identidad y movilización en los movimientos sociales", Zona Abierta n. ${ }^{9} 69$.

$"$ Box, C. y Posner, D. (1996). Making Social Capital Work. A review of Robert Putnam's Making Democracy Work. Paper $n^{9} 96-4$ Center for Intermational Affairs. Harvard: University of Harvard. LATTN, D.D. The Civic Culture al 30, en American Political Science Review, Vol. 89, No. 1 March 1995. TaRROW, S. •Making Social Science work Across Space and Time: a Critical Reflection on Robert Putnams Making Democracy Work, en American Political Science Review, Vol. 90, No. 2, 1996. Woolcock, M. op. cit.

12 Martínez, P. (1994). .La tradición asociativa en la sociedad catalana, en Documentación Social. Revista de Estudios Sociales y Sociología Aplicada. n. 94.

"SerRavo, M.A. (1997). La ciudad de las bombas. Barcelona y los años trágicos del movimiento obrero. Madrid: Temas de Hoy.

" COSTA I RIERA, J. (1997) Dels Moviments d'esglesia a la militància politica. Barcelona: Editorial Mediterrànea.

${ }^{1}$ CASTEUS, M. (1980) La ciudad y las masas. Sociología de los movimientos sociales urbanos. Madrid: Alianza.

16 SARASA, S. (1998) •Asociaciónisme, Moviments Socials i Participació Civica, en GlNER, S. La Societat Catalana. Barcelona: Generalitat de Catalunya.

$r^{-}$Es importante distinguir a partir de este período entre los movimientos sociales urbanos y los que simplemente se pueden definir como movimientos sociales, cuyos objetivos no tendrían un ámbito territorial definido circunscrito a la ciudad, ni reivindicarian necesariamente cuestiones de consumo colectivo.

19 BRUGute, Q. y Gomà, R.(1998) -Gobiemo local de la nacionalización al localismo y de la gerencialización a la repolitización., en BRUGUÉ, Q. y GoMà, R. Gobiernos Locales y Políticas Públicas. Bienestar social, promoción económica y territorio. Barcelona: Ariel.

19 Como por ejemplo los que tienen su origen en formas de capital social y cooperación anteriores a la guerra civil, de origen catalanista y estrictamente de clase obrera.

3. Esta normativa sólo fue posible dentro del marco más amplio de la Ley Reguladora de Bases de Régimen Local que se aprobó en 1985, que permitía a los municipios establecer unidades territoriales de gestión descentralizada, con la organización, funciones y competencias que cada gobiemo local les otorgue y con el objeto de mejorar la gestión local y facilitar la participación ciudadana. (L.R.B.R.L, art. 24).

-I Las competencias eran las siguientes: seguridad en lugares públicos, tráfico, bomberos, legislación, diseño y ejecución de los planes urbanísticos, monumentos históri- cos, protección medioambiental, mercados públicos y defensa del consumidor, cementerios, servicios sociales, suministro eléctrico y agua, limpieza, cultura y deportes y gestión de las escuelas (Normas Reguladoras de Ordenación de los Distritos y de la Participación Ciudadana, art. 5)

$\because$ Amorós, M. (1995) -Decentralization and new govemance: a comparison between Barcelona and Birmingham. Institut de Ciencies Politiques i Socials. Working Paper $n^{9}$ 10. Barcelona.

2.3 Organizatció Territorial i Participació Ciutadana a Barcelona, 1979-95. Ajuntament de Barcelona, Ámbit de Descentralizació i Relacions Ciutadanes.

$\therefore$ KNUDSEN establece, a propósito de la participación de los trabajadores en la empresa, los ámbitos en que puede tener lugar la participación. En el ámbito estratégico se definen los objetivos generales. En el ámbito de las decisiones tácticas se definen decisiones que afectan a la realización de esos objetivos. Las decisiones operativas hacen referencia a las pautas de ejecución de los objetivos. KNUDSEN incluye un cuarto ámbito de participación en la empresa, las decisiones de bienestar social. que viene a ser el escalón más básico de la participación y generalmente más inocuo para la empresa. KvudSEN, H. (1995) Employee Participatión in Europe. London: Sage.

En el caso de las Administraciones públicas podria sustituirse y en las organizaciones e.npresariales podría complementar el término de información como último nivel de posible participación en el proceso de toma de decisiones.

: El voto preferente en Italia consiste en que en un sistema de listas cerradas, el votante puede otorgar de manera opcional su voto a un candidato de la lista que haya elegido.

* Bienes privados:

Pr1: Consumo colectivo: asociaciones de vecinos, usuarios, inmigrantes (apoyo), consumidores, medios de comunicación locales, etc.

Pr2: Nueva cultura políica: solidaridad, género, medioambiente y economía social. Pr3: Organizaciones religiosas: parroquias con tejido asociativo, asistencia, grupos de ayuda mutua.

Pr4: Asistenciales: laicas: tercera edad, fundaciones no religiosas, asistencia, grupos de ayuda mutua.

Pr5: Fines culturales: fundaciones, organizaciones científicas y de difusión cultural. Bienes públicos

Pb1: Ocio y cultura popular

$\mathrm{Pb} 2$ : Cultura y Educación

Pb3: Deportes

Pb4: Entidades confesionales

Pb5: Entidades culturales específicas

Pb5a: Asociaciones regionales de fuera de Cataluña.

$\mathrm{Pb} 5$ b: Asociaciones de cultura catalana tradicional.

Pb5c: Asociaciones de nacionalismo catalán.

$\mathrm{Pb} 5 \mathrm{~d}$ : Asociaciones culturales extranjeras.

$\because$ Los datos mostrados proceden de la base de datos de la Agencia Municipal de Servicios a las Asociaciones, del Ayuntamiento de Barcelona, y corresponden a 1998. No existe otro registro de estas características más detallado. El grado de fiabilidad es relativamente alto, puesto que está siendo continuamente actualizado. A la información cuantitativa hay que añadir las más de treinta entrevistas realizadas a líderes vecinales de todos los distritos y a políticos y técnicos de todos los Distritos y del Ayuntamiento.

* Barcelona en xifres (1997). Departament de Estadística. Barcelona: Ajuntament de Barcelona. Cuando hablamos de Barcelona como segunda ciudad española nos estamos refiriendo a su área metropolitana que incluye municipios como L'Hospitalet, Badalona, Sant Adriá, etc., y que en la práctica están ligadas territorial y funcionalmente a Barcelona.

*) Por cuestiones de espacio, no se incluye la tabla general que contiene información sobre las entidades de ámbito extraterritorial y territorial.

4. SARASA, S. op. cit.

"Las asociaciones de inmigrantes de apoyo mutuo y de solidaridad con estos colectivos, son consideradas como productoras de bienes públicos, de consumo colectivo y nueva cultura política, y no son incluidas en esta categoría.

:" Hemos obviado los datos respecto a los tipos de entidades o asociaciones a que se pertenece, correspondientes a 1990 por estar distorsionados debido a un fallo de 
diseño que hace que entre 1985 y 1990 la tasa de gente que declara pertenecer a asociaciones de vecinos pasa en Barcelona ciudad de un 3, 3\% a un 9,3\%. En la edición de 1995 esta tasa desciende a 8,6\% una vez subsanado el defecto, lo que sigue siendo bastante elevado. Una posible explicación, desde nuestro punto de vista, sería la fomación de núcleos asociativos plurales en tomo a las asociaciones de vecinos tradicionales. Encuesta de la Región Metropolitana de Barcelona años 1990 y 1995 . Barcelona: Mancomunitat de Municipis de l'Área Metropolitana de Barcelona.

"Fundamentalmente, el Consell Municipal de Benestar Social, los Consells de Dona, Gent Gran, Joves, Inmigració, que dependen del Ámbit de Benestar Social del Ayuntamiento de Barcelona.

"Io $n^{2}$ de habitantes $/ n^{2}$ de asociados

"La numeración del Ayuntamiento de Barcelona es la siguiente: 1 . Ciutat Vella, 2. Eixample, 3. Sants-Montjuich, 4. Les Corts, 5. Sarriá-Sant Gervasi, 6. Grácia, 7. HortaGuinard6, 8. Nou Barris, 9. Sant Andreu, y 10. Sant Marti.

* Barcelona en Xifres (1997). Ajuntament de Barcelona. Barcelona: Departament d'estadistica. 5a excepción más notoria a esta cuestión se debe a que en el 2, Eixample, por su extensión y accesibilidad se ubican gran número de las entidades que ofrecen bienes públicos en el ámbito de la ciudad como conjunto, no tanto a nivel de distritos.

s. La distribución de la población de origen no catalán, exceptuando extranjeros, se distribuye en los seis distritos donde es más significativa de la siguiente manera: 8) $40,6 \%$; 7) $34,6 \%$; 9) $32,1 \%$; 10) $31,6 \%$, 1) $30,4 \%$; 3) $28,2 \%$. Ajuntament, op.cit.

3.) Los vecinos y las entidades denuncian el cobro indebido de una serie de conceptos del recibo del agua, y un buen número de asociaciones de vecinos tramitan sólo la parte que consideran legítima.

"Participació Ciutadana a l'Ajuntament de Barcelona (1998). Ajuntament de Barcelona.

"Participació ..., op. cit.

'- El carácter de las relaciones entre las autoridades del Distrito y las entidades ciudadanas, especialmente las asociaciones de vecinos, ha sido recogido mediante las entrevistas a unos y otros durante el inviemo de 1998. 


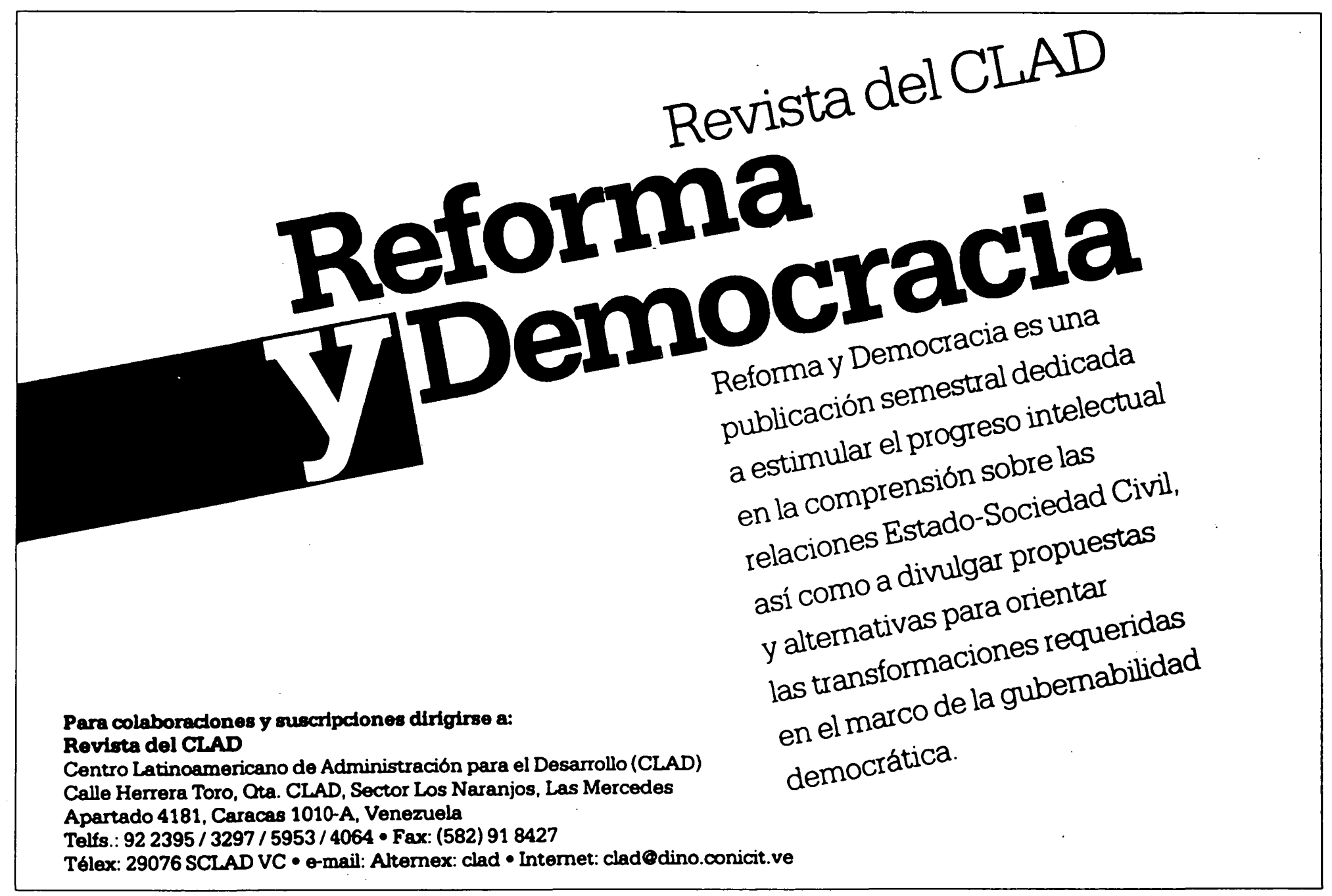

